\title{
Original Research Profile of drug utilization in the elderly living in Porto Alegre, Brazil
}

Fabiana TÔRRES FAGGIANI, Guilherme SCHROETER, Sandro LUZ PACHECO, Antônio Carlos ARAÚJO DE SOUZA, Maria Cristina WERLANG, Geraldo ATTÍLIO DE CARLI, Fernanda BUENO MORRONE.

\begin{abstract}
${ }^{*}$
The elderly population is one of the most rapidly increasing populations in the world. Physiological alterations induced by the aging process make these individuals more susceptible to chronic diseases and, consequently, to increased drug utilization.

Objective: To describe the profile of drug utilization in the elderly living in Porto Alegre, RS, Brazil. Methods: An observational and cross-sectional population-based study to investigate the characteristics of the population, sources of information and types of drugs used by the elderly was performed. Four hundred and eighty patients were recruited from data supplied by the City Hall of Porto Alegre. The elderly were interviewed individually during the period from January to May 2006 by trained interviewers. A validated pharmacotherapy questionnaire was used for data collection and data were tabulated and analyzed by the SPSS 11.5 computer program.

Results: Of the 480 patients interviewed, $13.8 \%$ did not use any medication. Cardiovascular system drugs represented the pharmacological class most used by the elderly (64.0\%). When ill, $71.9 \%$ of these individuals visited the doctor, while $36.9 \%$ self-medicated. For the majority $(50.2 \%)$, drugs were identified by their labels. Only $41.2 \%$ of the elderly understood medical prescriptions and $68.3 \%$ of the patients studied obtained the necessary information for the appropriate use of therapy from their doctors.
\end{abstract}

\footnotetext{
*Fabiana TÔRRES FAGGIANI. Faculty of Pharmacy, Pontifícia Universidade Católica do Rio Grande do Sul, Rio Grande do Sul (Brazil).

Guilherme SCHROETER. Faculty of Pharmacy, Pontificia Universidade Católica do Rio Grande do Sul, Rio Grande do Sul (Brazil).

Sandro LUZ PACHECO. Faculty of Pharmacy, Pontifícia Universidade Católica do Rio Grande do Sul, Rio Grande do Sul (Brazil).

Antônio Carlos ARAÚJO DE SOUZA. Geriatrics and Gerontologic Institute, Hospital São Lucas, Pontifícia Universidade Católica do Rio Grande do Sul, Rio Grande do Sul (Brazil).

Maria Cristina WERLANG. Faculty of Pharmacy, Pontifícia Universidade Católica do Rio Grande do Sul, Rio Grande do Sul (Brazil).

Geraldo ATTÍLIO DE CARLI. Faculty of Pharmacy and Geriatrics and Gerontologic Institute, Pontifícia Universidade Católica do Rio Grande do Sul, Rio Grande do Sul (Brazil).

Fernanda BUENO MORRONE. Faculty of Pharmacy, Pontifícia Universidade Católica do Rio Grande do Sul, Rio Grande do Sul (Brazil).
}

Conclusions: The present study suggests that a pharmaceutical care program for the treatment, prevention, and use of medications may provide a higher efficiency to elderly drug therapy.

Keywords: Drug Utilization. Polypharmacy. Aged. Brazil.

\section{RESUMEN}

La población anciana es una de las poblaciones que crece más rápidamente en el mundo. Las alteraciones fisiológicas producidas por la edad hacen a estos individuos más susceptibles a las enfermedades crónicas y, consecuentemente, a un aumento de uso de medicamentos.

Objetivo: Describir el perfil de utilización de medicamentos en ancianos que viven en Porto Alegre, RS, Brasil.

Métodos: Se realizó un estudio observacional transversal poblacional para investigar las características de la población, fuentes de información y tipos de medicamentos utilizados por los ancianos. Se reclutó a 484 pacientes de datos proporcionados por el Ayuntamiento de Porto Alegre. Se entrevistó a los ancianos individualmente durante un periodo de enero a mayo de 2006 por entrevistadores entrenados. Se usó un cuestionario farmacoterapéutico validado para la recogida de datos y los datos se tabularon y analizaron con el programa SPSS 11.5.

Resultados: De los 480 pacientes entrevistados, el $13,8 \%$ no utilizaban medicación. Los medicamentos del aparato cardiovascular representaban el grupo terapéutico más usado por los ancianos (64,0\%). Cuando enferman, el 71,9\% de estos individuos visitaron al médico, mientras que el 36,9\% se auto-medicó. Para la mayoría $(50,2 \%)$, identificaron los medicamentos por las etiquetas. Sólo el 41,2\% de los ancianos entendían las recetas médicas y el 68,3\% de los pacientes estudiados obtuvieron la información necesario de sus médicos.

Conclusiones: El presente estudio sugiere que un programa de atención farmacéutica para el tratamiento, prevención y uso de medicaciones puede proporcionar una mayor eficiencia a los tratamientos de los ancianos.

Palabras clave: Utilización de medicamentos. Polimedicación. Ancianos. Brasil. 


\section{(English)}

\section{INTRODUCTION}

The elderly population is steadily increasing and, currently, this age group demonstrates the fastest growth worldwide. This occurrence has long been observed in countries such as China and Japan, as well as in Europe and the United States and can lead to high costs to the State, provoking the need for serious and consistent policies. ${ }^{1}$ In Brazil, a developing country, the surge in growth of the elderly population has occurred more recently; the number of inhabitants aged sixty and over surpassed three million, in 1960, and 14 million in 2000 . $^{2}$ According to Braga et al., this situation is responsible for the high number of hospital admissions, the search for ambulatory services, the need for homecare and the use of pharmacotherapy. ${ }^{3}$

The elderly present peculiarities in regard to their use of medications, since the physiological alterations caused by the aging process make this population more susceptible to chronic diseases. ${ }^{4}$ Drug utilization becomes, as such, essential for elderly care, although, the incorrect use of medicines is one of the greatest problems experienced by this population. ${ }^{2,5}$ The unsupervised access to medications is related to a larger set of factors that includes access to medical and pharmacy services, as well as access to alternative sources of medications. The acquisition of pharmaceuticals, with or without a prescription, is dependent upon access to commercial sources of medications, such as pharmacies or drug peddlers. ${ }^{6}$

The elderly often use more than one drug, which may lead to drug interactions, adverse effects, concomitant use of other therapies and drug redundancy, and the use of drugs without therapeutic value. These events are, for the most part, related to pharmacodynamic and pharmacokinetic changes that occur at this age. ${ }^{3,7}$ Since an appropriate pharmacological therapy can minimize the symptoms of diseases and diminish mortality and morbidity indexes, population-based studies are needed to identify and quantify the most frequent prescription errors and their associated causes, providing numbers that can be analyzed and allowing for the identification of problems. Such information is considered to be of great importance due to the small number of epidemiological studies in this area, which may restrict the information available to health professionals and those responsible for public health policies. ${ }^{4,7,8}$

Since 1997, when a program for essential medicine distribution by the Brazilian government called "Programa Farmácia Básica" (PFB) was created, a new model for the training of pharmacists has been determined worldwide, in which it was established that every professional should be a good communicator. Effective communication is an essential tool for the Pharmaceutical Care practice because it improves the use of medications by patients, including the elderly, and ensures optimal therapeutic outcomes. Lyra et al. had observed that collaborative actions between physicians and pharmacists promoted changes in the elderly's drug regimens, in particular by adjusting drug therapy to the patients' routine schedules. Positive results of collaborative intervention, leading to the prevention and curing of diseases, reduction of treatment costs, and satisfaction with the Pharmaceutical Care program, has been shown. ${ }^{9}$

According to Santi, in the modern health system, the role of the health professional is to educate and orient the patient to the medications utilized, as well as other aspects of health care, such as the promotion of sanitary education. ${ }^{10,11}$ The present study aims to identify the drug utilization profile in the elderly of Porto Alegre, Rio Grande do Sul, Brazil.

\section{METHODS}

A population-based, cross-sectional, observational and exploratory study to investigate the characteristics and use of pharmacotherapy by the elderly was performed from January until May 2006. This study forms part of the Projeto Idosos de Porto Alegre, a partnership with the Porto Alegre City Hall and the Instituto de Geriatria e Gerontologia Pontifícia Universidade Católica do Rio Grande do Sul.

The sample number of this study was in accordance with the number of patients analyzed in a previous study (1995) for each quarter of Porto Alegre and was updated by the Instituto Brasileiro de Geografia e Estatística (IBGE) according to the estimation of the population variation through $2005 .^{12}$ For the sample size calculation we assumed a percentage of $0.69 \%$ to obtain a confidence interval of $99 \%$.

The patients interviewed were randomly recruited by the social service from different quarters and social conditions. City Hall provided the data on the different quarters where the elderly population was concentrated in Porto Alegre as well as the names and addresses of these individuals. Contact was made by telephone with the support of the Instituto de Geriatria and Gerontologia of the PUCRS.

Four hundred and eighty elderly individuals of both sexes were interviewed. Of these, some had access to medical and/or pharmaceutical assistance and some did not. To participate in this research study, the following inclusion criteria were used: individuals were not disabled (to allow for travel to the interview site) and were sixty or more years old. The patients who refused to participate to the study were excluded.

The interviews were conducted by trained interviewers (graduates, students and teachers). The instrument utilized was a previously validated pharmacotherapeutic questionnaire containing the actual therapy and information about the drug utilized. The questions were open ended and were answered based on the memory of the patient and/or through the use of materials supplied to the patient, such as prescriptions and/or a label. 
The drugs used by the patient at the time of the interview were considered. The following items about the drug utilization were evaluated: main pharmacological classes, number of drugs utilized, how the patients differentiated their medications, frequency of self-medication, frequency and place of drug attainment, understanding of medical prescriptions and sources of information regarding the consumed drugs and any action taken by the patient when sick. All drug administration, except that prescribed by a physician, was considered selfmedication. Polypharmacy was defined as the use of more than three drugs with the potential to cause drug interactions and side effects. ${ }^{13,14}$

The Institutional Ethics Committee of PUCRS approved this study (number 0502935). The Brazilian National Formulary 05/06 was utilized to identify the substances. The Anatomical Therapeutic and Chemical Classification System (ATC) was used to classify the drugs studied. ${ }^{15}$ The data were analyzed and tabulated using the SPSS computer program, version 11.5, and the results were presented as the percentage of the data set. Ninety-five percent confidence intervals $(95 \% \mathrm{Cl})$ were utilized to show difference in the patient's characteristics. ${ }^{16}$

\section{RESULTS}

Following interviews and the analysis of the data, it was verified that of the 480 elderly patients interviewed, $67.3 \%$ (323) were women. The age of the elderly interviewed varied between 60 and 88 years, with an average of $72.0 \quad(S D=6.3)$. Polypharmacy was common; $30.6 \%$ (148) used one or two drugs, $37.3 \%$ (179) used between three to five and $18.3 \%$ (88) utilized more than five drugs. The percentage of individuals interviewed that did not use medications was $13.7 \%(66)$. The average number of drugs by each individual was 3.8 $(\mathrm{SD}=2.6)($ Table 1).

\begin{tabular}{|l|c|c|}
\hline \multicolumn{2}{|l|}{ Table 1. Characteristics of the elderly population studied. } & $\begin{array}{c}\text { Confidence } \\
\text { Interval } \\
\text { IC } 95 \%\end{array}$ \\
\hline Characteristics & $\begin{array}{c}\text { Number of patients and } \\
\text { percentage }(\%) \\
(\mathrm{n}=480)\end{array}$ & \\
\hline Male & $122(25.5)$ & \\
\hline Female & $358(74.5)$ & $(23.5-31.5)$ \\
$60-64$ & $132(27.5)$ & $(30.5-39.1)$ \\
$65-74$ & $167(34.8)$ & $(27.3-35.7)$ \\
$75-84$ & $152(31.7)$ & \\
$\geq 85$ & $29(6.0)$ & $(10.7-16.1)$ \\
Average age & $72.0 \pm 6.3$ & $(26.7-35.0)$ \\
& & $(33.0-41.6)$ \\
Do not make use of medications & $66(13.7)$ & $(14.9-21.8)$ \\
One or two medications & $148(30.6)$ & \\
\hline Three to five medications & $179(37.3)$ & $88(18.3)$ \\
\hline
\end{tabular}

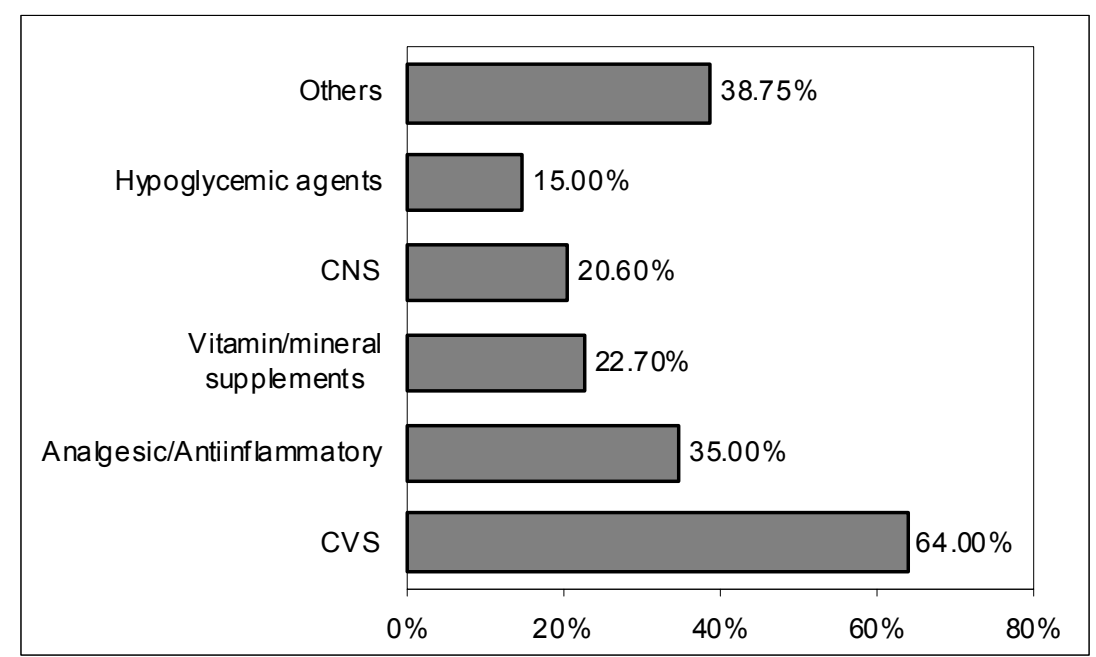

Figure 1. Pharmacological classes most used by the elderly interviewed $(n=480)$. Abbreviations: CVS (cardiovascular system); CNS (central nervous system). 
Figure 1 illustrates the pharmacological classes most used by the elderly. It can be seen that the most used class was the cardiovascular system drugs.

When the interviewees were questioned regarding the action taken in the case of a health problem, the majority responded that they consult a physician, but a considerable proportion of this population still self-medicated, asking for the opinion of other people, mainly those with whom they live, used the drugs that they have at home, or bought medications in the pharmacy without a prescription. In some cases, the elderly used more than one treatment form when they found that they were sick (Table 2).

\begin{tabular}{|c|c|c|}
\hline \multicolumn{3}{|c|}{$\begin{array}{l}\text { Table } 2 \text {. Action taken by the elderly in the case of a } \\
\text { health problem. }{ }^{*}\end{array}$} \\
\hline Action taken $(n=480)$ & Patients & $\%$ \\
\hline Consult a doctor & 345 & 71.9 \\
\hline $\begin{array}{l}\text { Use of medicines from their home } \\
\text { pharmacy }\end{array}$ & 120 & 25.0 \\
\hline $\begin{array}{l}\text { Buy medicines in the pharmacy } \\
\text { without prescription }\end{array}$ & 39 & 8.1 \\
\hline Ask for opinions of other people & 18 & 3.7 \\
\hline \multicolumn{3}{|l|}{ Prevalence of self-medication $(n=177)$} \\
\hline Women & 122 & 68.9 \\
\hline Men & 55 & 31.1 \\
\hline
\end{tabular}

Of the 480 interviewed, $73.9 \%$ (355) obtained all the drugs that they need, whereas $21.5 \%$ (103) did not. The percent of individuals that obtained their medications through public health centers was $50.6 \%$ (243); of these, $30.0 \%$ (73) were men and $69.9 \%$ (170) were women. If this was not possible, the elderly used commercial pharmacies $(68.9 \%$; 331 ) and compounding pharmacies $(24.4 \%$; 117$)$ instead. It is important to point out that some of the interviewed individuals obtained their drugs from two or more places.

The elderly were questioned about the system they used to identify different drugs. The most used manner of differentiation was to consult the label, used by $50.2 \%$ (241) of the interviewed individuals, of which $34.4 \%(83)$ were men and $65.5 \%(158)$ were women. The name $14.6 \%$ (70), color $9.4 \%$ (45) and size $3.9 \%$ (19) of the drugs were also employed to differentiate medications, among other methods described by those interviewed.

It was observed that most of the interviewed individuals acquired the information necessary for the accomplishment of an adjusted therapy from the doctor, as shown in Table 3. We also investigated the degree of understanding of the medical prescription by the elderly and found that only $41.2 \%(198)$ of this population were able to understand what was written on their medical prescriptions.

\section{DISCUSSION}

In this study, trained interviewers conducted 480 interviews with the elderly of Porto Alegre, RS, Brazil, all of whom were randomly chosen from different social conditions and quarters of the city. Thus, it was possible to verify the drug utilization profile of this population while diminishing biases, allowing for the consideration of the impact that social, economic and cultural differences can exercise on the conduct of the elderly in regard to the use of medicines. ${ }^{17}$ It is important to highlight that the difficulties that the elderly experience during the process of adherence to their pharmacotherapy were not fully explored. Furthermore, there is a gap in the knowledge available with regard to pharmacist interventions used to inform these users about their therapy.

Other studies reporting drug utilization by the elderly from different countries have already been performed and show a high incidence of polytherapy. ${ }^{19,20}$ Inappropriate use of medication is most frequent in patients taking many medications. ${ }^{21}$ This reality indicates that particular attention and care should be paid to the elderly to reduce the unnecessary use of drugs and in this way, contribute to the correct use of therapies. A study conducted by Braga et al. in Campinas (Brazil), demonstrated a mean number of 3.3 drugs in use by each elderly patient; this value was a little smaller than that found in previously published studies. $^{3,22}$

The elderly have a high index of cardiovascular problems, which are one of the main causes of death in this population. ${ }^{23-25}$ According to estimations, hypertension is the cause of $4.5 \%$ of all diseases globally, and is as prevalent in developing countries as in non-developed countries.26 As a consequence of this, cardiovascular drugs are highly utilized, as verified both in the present article as well as in previous studies. ${ }^{19,20,27}$

Table 3. Sources of information for the for the corrected use of drugs $(n=480)^{*}$

\begin{tabular}{|l|c|c|c|}
\hline & Patients & $\%$ & IC 95\% \\
\hline Physician & 382 & 68.3 & $(64.1-72.5)$ \\
\hline Medical prescription & 98 & 20.4 & $(16.8-24.0)$ \\
\hline Label & 83 & 17.3 & $(13.9-20.7)$ \\
\hline Family & 58 & 12.1 & $(9.2-15.0)$ \\
\hline Pharmacist & 54 & 11.2 & $(8.4-14.0)$ \\
\hline Pharmacy assistant & 30 & 6.2 & $(4.0-8.4)$ \\
\hline${ }^{*}$ Multiple choice question
\end{tabular}

The majority of the elderly look for medical assistance before the onset of diseases, which illustrates the rational preoccupation that this population has with their health. Nevertheless, in small communities and in big cities, the pharmacy has an important role in the informal network of healthcare. ${ }^{28}$ Although, self medication still occurs, possibly contributing to the substitution mechanism for the formal attention to health, this finding has also been observed in other international studies.

Comparing our results with other previously published studies, pharmacists in Brazil have a low rate of participation in the recommendation of overthe-counter drugs, however, the pharmacies were described as a being a source for the dispensing of medications. $^{2}$ Thus, we observe that the involvement of the pharmacy professional in the conduction of programs for the rational use of drugs by the geriatric population is indispensable. ${ }^{17,18}$ 
Generally, women have a greater preoccupation with health and consult health services more than men. Zaitune et al. showed, in a study performed in Campinas (Brazil), that various programs in this area, such as the pre-natal program and colon and breast cancer prevention programs, are developed for women; as such, women are more accustomed to the use of drugs. These factors could explain, at least partially, the greater use of medications by this group. 29

In the present study, it was shown that the majority of the elderly population of Porto Alegre manages to acquire the medications that they need. However, despite the existence of a program of essential medicine distribution (PFB) in Brazil with the objective of making medicines accessible to this population, a considerable proportion of this population still does not adhere to necessary therapies for their health because they cannot acquire some of the drugs needed. ${ }^{30}$ This fact demonstrates an existing failure in the Public health system, since public health centers should distribute medicines to the population. It also suggests that there is a lack of disclosure to this population about how to acquire their therapy for free.

Since the medicine labels were indicated as the main method of differentiating between the different drugs that each elderly patient consumes, we should consider developing adequate labels to overcome the limitations of this population, mainly in regard to visual deficiencies and difficulties in remembering previous instructions. This practice aims to diminish the degree of confusion that occurs at the time that the patient administers his/her medications, due to the great number of drugs utilized by each elderly individual.

The results regarding the source of information and the adequate drug administration indicate the need for legible and explicative drug prescriptions, since a great proportion of the elderly population do not understand their drug prescriptions or the correct procedure for the use of the drugs prescribed. It should be further noted that family members and pharmacy assistants (less qualified professionals) should be educated as to the potential implications of drug use without constraints by the elderly, since it is clear that these professionals, at least in Brazil, still provide this kind of information, increasing the risk of drug interactions and side effects. ${ }^{5}$

Thus, we observe the need for clear indications and very clear and detailed information about the use of drugs, to provide greater efficacy for the pharmacotherapy employed for the aged. Incorrect or unclear prescriptions can interfere with the quality of medicines consumed, and should contain the maximum amount of information possible so that the elderly do not have any doubts at the moment of drug administration.

\section{CONCLUSIONS}

In this study, we described the profile of drug use by the elderly in Porto Alegre in the South of Brazil. Cardiovascular drugs were the main class utilized by the population and the rates of use of polytherapy and self medication were high. New studies are necessary to evaluate the needs of the elderly with regard to their drug use so that pharmaceutical care programs can be developed specifically to avoid the failures of the current therapy and to prevent drug related problems.

\section{ACKNOWLEDGMENTS}

This study was financed by the Conselho Nacional Desenvolvimento Científico e Tecnológico (CNPq) and the Municipal City hall of Porto Alegre, RS. The study also received logistic support from the Pharmacy College, Hospital São Lucas da PUC and Instituto de Geriatria e Gerontologia PUCRS. The authors thank American Journal Experts for the English correction.

\section{CONFLICT OF INTEREST}

None declared.

\section{References}

1. Garrido R, Menezes PR. [O Brasil está envelhecendo: boas e más notícias por uma perspectiva epidemiológica]. Rev Bras Psiquiatr 2002;24(1):3-6.

2. Loyola Filho AI, Uchoa E, Firmo Jde O, Lima-Costa MF. [A population-based study on use of medications by elderly Brazilians: the Bambuí Health and Aging Study (BHAS)]. Cad Saúde Pública 2005;21(2):545-53.

3. Braga TB, Pfaffenbach G, Weiss DP, Barros MB, Bergsten-Mendes G. Point prevalence of drug prescriptions for elderly and non-elderly inpatients in a teaching hospital. Sao Paulo Med J 2004;122(2):48-52.

4. Acurcio Fde A, Rozenfeld S, Ribeiro AQ, Klein CH, Moura CS, Andrade CR. [Use of medications by elderly Brazilian retirees: 1--methodology and response rates of a multicenter survey]. Cad Saude Publica 2006;22(1):87-96.

5. Romano-Lieber NS, Teixeira JJ, Farhat FC, Ribeiro E, Crozatti MT, de Oliveira GS. [A literature review on pharmacists' interventions in the use of medication by elderly patients]. Cad Saude Publica 2002;18(6):1499-507.

6. Miralles MA, Kimberlin CL. Perceived access to care and medication use among ambulatory elderly in Rio de Janeiro, Brazil. Soc Sci Med 1998;46(3):345-55.

7. Brekke M, Hunskaar S, Straand J. Self-reported drug utilization, health, and lifestyle factors among 70-74 year old community dwelling individuals in Western Norway. The Hordaland Health Study (HUSK). BMC Public Health. 2006;6:121.

8. Mosegui GB, Rozenfeld S, Veras RP, Vianna CM. [Quality assessment of drug use in the elderly]. Rev Saude Publica 1999;33(5):437-44. 
9. Lyra DP Jr, Rocha CE, Abriata JP, Gimenes FR, Gonzalez MM, Pelá IR. Influence of Pharmaceutical Care intervention and communication skills on the improvement of pharmacotherapeutic outcomes with elderly Brazilian outpatients. Patient Educ Couns 2007;68(2):186-92.

10. Santi V. Processos de mudanças nas atividades do farmacêutico, pp. 33-41. Anais da I Conferência Nacional de Educação Farmacêutica; 2000; Brasília, Brasil.

11. Néri EDR, Oliveira SGM, Rodrigues JLN, Medeiros MMC, Fonteles MMF. Erros na área da saúde: culpado ou inocente? Infarma 2006; 18: 3-4.

12. Instituto Brasileiro de Geografia e Estatística (IBGE). Disponível em http://www.ibge.gov.br. Acesso em 11 abr. 2006.

13. Evans JG. Drugs and falls in later life. Lancet. 2003;361(9356):448.

14. Frankfort SV, Tulner LR, van Campen JP, Koks CH, Beijnen JH. Evaluation of pharmacotherapy in geriatric patients after performing complete geriatric assessment at a diagnostic day clinic. Clin Drug Investig 2006;26(3):169-74.

15. WHO. World Health Organization. Anatomical-Therapeutic-Chemical Classification - ATC 2004. In: http://www.whocc.no/atcddd; 2004.

16. Zar J.H. Biostatistical Analysis. Fourth Edition. New Jersey: Prentice Hall; 1999. ISBN 013086398X.

17. Coelho Filho JM, Marcopito LF, Castelo A. [Medication use patterns among elderly people in urban area in Northeastern Brazil]. Rev Saude Publica 2004;38(4):557-64.

18. Cordero L, Cadavid MI, Fernández-Llimós F, Díaz C, Sanz F, Loza MI. Continuing education and community pharmacists in Galicia: a study of opinions. Pharm World Sci 2004;26(3):173-7.

19. Chen YF, Dewey ME, Avery AJ; Analysis Group of The MRCCFA Study. The Medical Research Council Cognitive Function and Ageing Study (MRC CFAS). Self-reported medication use for older people in England and Wales. J Clin Pharm Ther 2001;26(2):129-40.

20. Linjakumpu T, Hartikainen S, Klaukka T, Veijola J, Kivelä SL, Isoaho R. Use of medications and polypharmacy are increasing among the elderly. J Clin Epidemiol 2002;55(8):809-17.

21. Steinman MA, Landefeld CS, Rosenthal GE, Berthenthal D, Sen S, Kaboli PJ. Polypharmacy and prescribing quality in older people. J Am Geriatr Soc 2006;54(10):1516-23.

22. Teixeira JJ, Lefèvre F. [Drug prescription from the perspective of elderly patients]. Rev Saude Publica 2001;35(2):20713.

23. Flores LM, Mengue SS. [Drug use by the elderly in Southern Brazil]. Rev Saude Publica 2005;39(6):924-9.

24. Ali Raza J, Movahed A. Use of cardiovascular medications in the elderly. Int J Cardiol 2002;85(2-3):203-15.

25. Firmo JO, Lima-Costa MF, Uchôa E. [The Bambuí Health and Aging Study (BHAS): ways of thinking and acting among hypertensive older adults]. Cad Saude Publica 2004;20(4):1029-40.

26. Whitworth JA; World Health Organization, International Society of Hypertension Writing Group. 2003 World Health Organization (WHO)/International Society of Hypertension (ISH) statement on management of hypertension. J Hypertens 2003;21(11):1983-92.

27. Barat I, Andreasen F, Damsgaard EM. The consumption of drugs by 75 -year-old individuals living in their own homes. Eur J Clin Pharmacol 2000;56(6-7):501-9.

28. Queiroz MS. [Strategies for consumption of health care by working-class families]. Cad Saude Pública 1993;9(3):27282.

29. Zaitune MP, Barros MB, César CL, Carandina L, Goldbaum M. [Arterial hypertension in the elderly: prevalence, associated factors, and control practices in Campinas, São Paulo, Brazil]. Cad Saude Publica 2006;22(2):285-94.

30. Cosendey MA, Bermudez JA, Reis AL, Silva HF, Oliveira MA, Luiza VL. [Pharmaceutical care in primary health care: the experience of 3 Brazilian States]. Cad Saude Publica 2000;16(1):171-82. 